\title{
Satisfaction with malaria care among pregnant women and mothers of under-five years children in Ibadan, Southwest Nigeria
}

Kelechi Elizabeth Oladimeji ( $\nabla$ KOladimeji@ufh.ac.za )

University of Fort Hare https://orcid.org/0000-0002-0246-5595

Joyce Mahlako Tsoka-Gwegweni

University of the Free State

Sanni Yaya

University of Ottawa

Jerry John Nutor

University of California

Abiodun M Adeola

University of Pretoria

Samuel Nambile Cumber

University of the Free State

Francis Leonard Mpotte Hyera

Walter Sisulu University

Ter Daniel Goon

University of Fort Hare

\section{Research article}

Keywords: quality of care, patient satisfaction, malaria care, pregnant women, mothers of children under 5 years of age, Nigeria

Posted Date: September 14th, 2020

DOI: https://doi.org/10.21203/rs.3.rs-21684/v2

License: (c) (1) This work is licensed under a Creative Commons Attribution 4.0 International License. Read Full License 


\section{Abstract}

Background Patient satisfaction is as an important measure of program assessment and health system performance. In our study, we assessed patient's satisfaction with malaria care among pregnant women (PW) and mothers of children less than five years of age (MU5) in Ibadan, Nigeria.

Methods A cross-sectional design, patient satisfaction with malaria care was assessed among 1,373 participants (818 PW and 555 MU5) with the anti-malarial care they received in a comprehensive hospital in Ibadan, Nigeria. Data on patient satisfaction was obtained using a validated eighteen-item questionnaire (PSQ-18) and analyzed using the standard satisfaction scales and quantitative scores.

Results Majority of the study respondents were married and within the age group 25-34years. Overall, indecisive satisfaction (mean range of 3.0-3.99) was observed for items 4, 7, 9, 10, 12, 13, and 16 in the PSQ-18 tool. From the satisfaction sub-scales derived, lowest mean score reflecting poor satisfaction (mean 2.96) was observed for the domain 'time spent with doctor' among the pregnant women, while in mothers of children aged under five years, poor satisfaction (mean 2.95) was observed for the general satisfaction sub-scale. Results of the multivariate analysis showed that pregnant women in the upper socioeconomic class had statistically significant lower odds of satisfaction (OR: $0.29,95 \% \mathrm{Cl}: 0.10-0.84$ ) with the interpersonal way malaria care was provided. Among mothers of children less than five years old, education and socioeconomic status were significant predictors of higher odds of satisfaction with financial aspects of malaria care.

Conclusion Socio economic status and one of its indicators, education plays significant roles in mothers' satisfaction with health care access, level of care received and most importantly their prospective health seeking behaviour. Important aspect, such as patient's perception of being well treated by the health care provider should be a key consideration for formulate a patients' centred strategy to improve health care for malaria in malaria endemic settings.

\section{Background}

Despite an unprecedented success in malaria control worldwide, malaria continues to be the leading cause of childhood and maternal mortality. In 2018, 67\% (272 000) of all malaria deaths worldwide were among children under five (5) years of age, while $27 \%$ of all malaria cases in sub-Saharan Africa were among pregnant women. Further, the World Health Organization (WHO) Africa region continues to bear more than $90 \%$ of the global malaria burden with Nigeria having the highest (25\%) malaria cases followed by the Democratic Republic of the Congo (12\%), Uganda (5\%), and Côte d'Ivoire, Mozambique and Niger (4\% each) [1]. According to the recent Nigeria Malaria Indicator Survey (NMIS), the country has demonstrated progress in reducing malaria prevalence among children less than 5 years old, from $42 \%$ in 2010 to $27 \%$ in 2015 [2]. The national malaria response supports the promotion of insecticide-treated mosquito nets (ITNs), indoor residual spraying (IRS), intermittent preventive treatment for pregnant women (IPT) and prompt diagnosis and treatment [3]. Even with these efforts at malaria control, the rate of progress across the country is not uniform. Some of the challenges responsible for the variance and slowprogress in reducing malaria burden to pre-elimination levels and achieving zero malaria-related mortality include weaknesses in the Nigerian health care system $[2,4]$.

Identifying weaknesses in health care systems using patient-centered approaches is important for improved and strategic health care planning [5]. Over the past years, patient satisfaction surveys have gained increasing attention as meaningful and essential source of information for identifying operational gaps and developing an effective 
intervention for quality improvement in healthcare delivery [6, 7]. Patient satisfaction refers to the patient's perception of care received compared with the care expected [8]. There are very few published studies on patient satisfaction with malaria care in sub-Saharan Africa, particularly in Nigeria. More studies are needed to inform policy makers on the needs of patients and to influence the development of strategic plans for provision of improved health care services [7]. The Nigerian national malaria policy launched in February 2015 stated the country's aim is to provide cost effective and equitable malaria elimination services while ensuring transparency, accountability and patient satisfaction [9]. The present study set out to evaluate the level of satisfaction with malaria health care services among pregnant women and mothers of children under 5 years of age in Ibadan, South West Nigeria.

Maternal categories (pregnant women and mothers of children under five years of age) were targeted for the ascertainment of their satisfaction with malaria care because pregnant women and children under five years of age are vulnerable populations that are worse affected by malaria burden [1]. Besides, evidence has shown that satisfaction with healthcare influences health-seeking behaviour, uptake of preventive measures, adherence to treatment and health outcomes [10]. While children under the age of five are too young to make health decisions and take care of themselves, mothers play an important role in ensuring their children's health and wellbeing [11]. Therefore, determining levels and facilitators of satisfaction with malaria care by mothers of children under five years and pregnant women is necessary to provide insights on specific strategies and polices that can be directed at women to improved uptake of current malaria interventions and reduce the burden of malaria in children less than five years and pregnant women.

\section{Methods}

\section{Study design and setting}

This cross sectional study was conducted between May and September, 2016 at the Adeoyo maternity hospital, which is the largest secondary maternity hospital in Ibadan, Oyo State, Nigeria [12]. Ibadan is the second most populated city in Nigeria's southwest region with total population of about 2,550,593 based on the 2006 national census [13].

Ibadan is zone one in the distribution of local government areas (LGAs) in Oyo state and it is comprised of 11 LGAs namely; Egbeda, Oluyole, Akinyele, Ona-ara, Lagelu, Ido, Ibadan North East, Ibadan North West, Ibadan South East, Ibadan South West and Ibadan North [14].

\section{Study population and sampling}

This study population included consenting pregnant women and mothers of children under 5 years old. Women who resided in Ibadan and presented to the antenatal clinic or outpatient children's clinic for care based on self-reported malaria symptoms were eligible to participate in the study. In the enrolment of study participants, we applied a three-stage sampling technique where each stage involved a simple random sampling of each sample unit from the respective sampling frames. The first stage involved a simple random selection of zone 1 (Ibadan) from the study sampling frame consisting of a list of all LGAs in Oyo State categorized into five (5) zones [14]. Similarly, the second stage involved the simple random selection of Adeoyo maternity hospital as the study site from the sampling frame that included all maternity hospitals in Ibadan. This selected study site is located in Ibadan Northeast LGA and is accessible to residents living in all LGAs within each zone in Oyo state. Lastly, at the third stage, eligible consenting 
study participants were selected using simple random sampling from the study site (the sampling frame at this third stage) and enrolled in the study.

\section{Data collection instrument - The patient satisfaction questionnaire (PSQ-18)}

The Patient Satisfaction Questionnaire (PSQ-18) developed by the RAND corporation is a unique short version of the older questionnaire (PSQ-III) that has 50 questions designed by Ware et al. in 1976 [15-17]. Both the PSQ-III and the PSQ-18 can assess satisfaction with medical care under these categories: general satisfaction, technical quality, interpersonal manner, communication, financial aspects of care, time spent with the doctor, and accessibility of care. The PSQ-18 has 18 questions and has been validated for use in different settings after extensive research has maintained internal consistency and reliability $[12,15,16,18]$. There is also a scoring guide to be used in the analysis of the data collected with the tool. Both the PSQ-18 and the Scoring Guide is available in the Rand Corporation website [19] and, is available in the supplementary files for this study. Since evidence has shown the validity of the PSQ-18 for use in different settings [16], we only tested it to ensure comprehension by both our study trained interviewers and participants prior actual data collection.

\section{Data collection}

Data was collected using the validated eighteen-item patient satisfaction questionnaire (PSQ-18) [19]. Socio demographic information was collected using a modified validated demographic health survey (DHS) questionnaire [18]. Eligible study participants were randomly selected and interviewed by study trained research assistants using both the DHS questionnaire and PSQ-18 after signed informed consents were obtained.

\section{Data analysis}

Based on a documented guide for the PSQ-18 analyses as earlier mentioned $[19,20]$, all items in the PSQ-18 tool were scored from one to five (1-5). Some PSQ-18 items are worded so that agreement reflects satisfaction with medical care, whereas other items are worded so that agreement reflects dissatisfaction with medical care; 'Agree or strongly agree' = 'Satisfaction' for Items 1, 2, 3, 5, 6, 8, 11, 15 and 18. Similarly, 'Disagree or strongly disagree' = 'Satisfaction' for Items 4, 7, 9, 10, 12, 13, 14, 16 and 17. Therefore, the scoring system was such that the original responses for items $1,2,3,6,8,11,15$, and 18 were reversed. Eventually, satisfaction with health care was expressed using means and standard deviation where high mean scores (4-5) indicates higher satisfaction with malaria care.

Further, seven different scales of satisfaction (dependent variables) were derived from each item in the PSQ-18 as follows: General Satisfaction (Items 3 and 17); Technical Quality (Items 2, 4, 6, and 14); Interpersonal Manner (Items 10 and 11); Communication (Items 1 and 13); Financial Aspects (Items 5 and 7); Time Spent with Doctor (Items 12 and 15); Accessibility and Convenience (Items 8, 9, 16, and 18). All items in each of these domains were scored from 0 to five (0-5) so that high mean scores (4-5) reflect good satisfaction in all domains, while low mean scores indicate poor satisfaction (1-2).

Logistic regression was used to explore significant predictors of each satisfaction sub-scale from the respondent characteristics (independent variables). A cut-off of $\leq 5$ and 6-10 was applied for domains with 2 items and $\leq 10$ and 11-20 were applied for domains with 4 items. This cut-off was carried out to dichotomize the dependent variables (each of the sub-scales of satisfaction). A bivariate logistic regression analysis was first conducted for all independent variables, and only those found to be statistically significant using significance level $(P$ value $)$ set at $<0.05$ were included in a multivariate analysis. Multivariate analysis (where applicable) was done to adjust for the 
effect of confounders. All ORs were reported with their $95 \% \mathrm{Cl}$ and corresponding $P$-values. Data analyses were conducted with the Statistical Package of Social Sciences (SPSS) version-25 and STATA version15.

\section{Results}

\section{Socio-demographic and clinical characteristics}

The mean age of mothers of children under 5 years of age was $29.3 \pm 5.2$ years. The predominant age group between both maternal groups in the study was women aged $25-34$ years of age (69.5\% of all participants). Majority of the respondents (60.9\%) were within the lower upper socio-economic class, had secondary education (51.6\%) as the highest level of education attained and married (90.8\%) (Table 1).

\section{Table 1: Socio-demographic and clinical characteristics of the respondents}


Variables

Respondents group

\begin{tabular}{lll} 
Variables & Number (n) & Percentage (\%) \\
\hline Respondents group & & \\
\hline Pregnant women & 818 & 59.6 \\
\hline Mothers of Children Under 5 years of age & 555 & 40.4 \\
\hline Age group (years) & & \\
\hline$<24$ & 207 & 15.1 \\
\hline $25-34$ & 954 & 69.5 \\
\hline $35+$ & 212 & 15.4 \\
\hline
\end{tabular}

Mean 29.3, SD 5.2; Range: 19-98years

\section{Socio economic status}

\begin{tabular}{|c|c|c|}
\hline Lower class & 202 & 14.8 \\
\hline Lower middle class & 219 & 16.0 \\
\hline Lower upper class & 833 & 60.7 \\
\hline Upper class & 115 & 8.4 \\
\hline \multicolumn{3}{|l|}{ Marital status } \\
\hline Never married & 42 & 3.1 \\
\hline Married & 1261 & 91.8 \\
\hline Separated/Widowed & 70 & 5.1 \\
\hline \multicolumn{3}{|l|}{ Education } \\
\hline No formal education & 97 & 7.1 \\
\hline Primary & 81 & 5.9 \\
\hline Secondary & 709 & 51.6 \\
\hline Tertiary & 486 & 35.4 \\
\hline \multicolumn{3}{|l|}{ Religion } \\
\hline Christianity & 567 & 41.3 \\
\hline Islam & 784 & 57.1 \\
\hline Traditional worshipper & 22 & 1.6 \\
\hline \multicolumn{3}{|c|}{ Respondents number of children } \\
\hline Pregnant with first child & 275 & 20.0 \\
\hline Has more than one child & 1098 & 80.0 \\
\hline
\end{tabular}

Number (n) Percentage (\%) 


\section{Satisfaction with malaria care}

Table 2 shows the summary of respondents' satisfaction with malaria care for each item on the PSQ-18. Higher satisfaction (mean score of 4 and above) was observed for items 1, 2, 3, 5, 6, 8 and 11, of which highest satisfaction was for item 1 (Doctors/health staff are good at explaining the reason for malaria test/s). However, this highest satisfaction seen for item 1 was only among a few $(21,2.3 \%)$ of the respondents $(925)$ who provided responses. Conversely, lowest level of satisfaction (mean score 1.67, SD 0.87) was found for item 17, where majority of the respondents $(763,86.7 \%)$ reported dissatisfaction with some aspects of treatment received for malaria infection. Indecisive satisfaction was observed for items 4, 7, 9, 10, 12, 13, and 16 .

We further explored sub-scales of satisfaction for each of the PSQ-18 items using the analysis scoring guide discussed earlier in the methods section. A summary of the satisfaction level for each of the seven (7) satisfaction domains derived is shown in Table 3. Across both maternal categories in the study, there were not huge differences in the levels of satisfaction for each satisfaction sub-scale as the mean differences ranged from 0.07 to 0.15 . Both maternal categories had a higher level of satisfaction for communication, interpersonal manner and financial aspects satisfaction domains. However, in both maternal groups, the highest mean score was observed for communication sub-scale (indicating higher satisfaction) even though the mothers of children aged five years were more satisfied (mean difference $=0.11$ ). Among the pregnant women, lowest mean score (indicating poor satisfaction) was observed for the domain 'time spent with doctor' while among mothers of children aged under five years, lowest mean score was observed for general satisfaction domain.

Table 2: Respondents Satisfaction levels for each of the eighteen items 


\section{Questions (Items)}

Satisfaction for each of the items in the PSQ-18

\begin{tabular}{|c|c|c|c|c|}
\hline $\begin{array}{l}\text { No (Strongly } \\
\text { disagree } \\
\text { and } \\
\text { disagree }\end{array}$ & $\begin{array}{l}\text { Uncertain } \\
\text { n (\%)n } \\
(\%)\end{array}$ & $\begin{array}{l}\text { Yes } \\
\text { (Strongly } \\
\text { agree } \\
\text { and } \\
\text { agree) }\end{array}$ & $\begin{array}{l}\text { Mean of } \\
\text { responses } \\
1-5\end{array}$ & $\begin{array}{l}\text { Standard } \\
\text { Deviation }\end{array}$ \\
\hline
\end{tabular}

n (\%)

n (\%)

Q1 - Doctors/health staff are good at explaining the reason for malaria test/s, $\mathrm{N}=$ 925

Q2 - I think the health facility has everything needed to provide complete care, $\mathrm{N}=923$

Q3 - The malaria intervention I have been receiving is just about perfect, $\mathrm{N}=910$

Q4 - Sometimes doctors make me wonder if 382 (42.9) their diagnosis is correct, $\mathrm{N}=891$

Q5 - I feel confident that I can get the malaria intervention/s I need without being set back financially, $\mathrm{N}=907$

Q6 - When I go for medical care, they health staff are careful to check everything when treating and examining me, $\mathrm{N}=912$

\section{Q7 - I have to pay for more of my medica care than I can afford, $\mathrm{N}=913$ \\ Q8 - I have easy access to the medical specialists I need, $\mathrm{N}=905$ \\ Q9 - When I get care for malaria, people have to wait too long for emergency treatment, $\mathrm{N}=906$}

$850(92.1)$

$829(91.1)$

788 (86.9)

$776(85.1)$

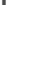

469 (51.8)
$861(93.1)$
43 (4.6)
$21(2.3)$
4.35
0.71

49 (5.3) $\quad 24(2.6)$

4.24

0.69

$65(7.1) \quad 16(1.8)$

4.30

0.69

189

(21.2)

320

(35.9)

3.10

1.25

74 (8.1)

45 (5.0)

4.21

0.83

$45(5.0) \quad 4.21 \quad 0.83$

$87(9.5)$

49 (5.4)

4.18

0.82

$552(60.5)$

109

(11.9)

252

(27.6)

3.41

1.18

$733(81.0) \quad 90(9.9)$

$82(9.1)$

4.10

0.95

127

(14.0)

310

(34.2)

3.21

1.24

\section{5}

(17.1)

213

(23.5)

3.42

1.15

539 (59.4)

$\mathrm{N}=907$

Q11 - My doctors/nurse treat me in a very

friendly and courteous manner,

$89(9.8)$

125

(13.8)

4.01

1.06

$N=908$

694 (76.4) 
Q12 - Those who provide medical care sometimes hurry too much when they treat me for malaria, $\mathrm{N}=905$

$607(67.1)$

115

(12.7)
183

(20.2)
Q14 - I have some doubts about the ability of the doctor who treat me, $\mathrm{N}=907$
119

(13.1)
624

(68.8)
2.17

1.09

$164(18.1)$

$201(22.8)$

$94(10.7)$

585

(66.5)

2.46

1.20

with me, $\mathrm{N}=880$

Q16 - I find it hard to get an appointment for medical care, $\mathrm{N}=890$

$620(69.7)$

101

(11.3)

169

(19.0)

3.62

1.10

$57(6.5) \quad 763$

(86.7)

1.67

0.87

$60(6.8)$

Q17 - I am dissatisfied with some things
about the malaria treatment I receive, $\mathrm{N}=880$

$154(17.2)$

$82(9.2)$

657

(73.6)

1.07

whenever I need it, $\mathrm{N}=893$

eatment

According to the instructions for scoring Patient Satisfaction Questionnaire 18 (PSQ-18) [19]

(i) 'Agree or strongly agree' = 'Satisfaction' for Items 1, 2, 3, 5, 6, 8, 11, 15 and 18.

(ii) 'Disagree or strongly disagree' = 'Satisfaction' for Items 4, 7, 9, 10, 12, 13, 14, 16 and 17.

(iii) For all 18 items, means can range from 1 (strongly dissatisfied) to 5 (strongly satisfied). The results are coded in such a way that, the closer the means are to ' 5 ', the higher the satisfaction level for ALL the items.

Table 3: Seven Scales of Satisfaction Items in Table 2 


\begin{tabular}{|c|c|c|c|c|c|c|c|}
\hline \multirow[t]{2}{*}{ SN } & \multirow{2}{*}{$\begin{array}{l}\text { Satisfaction } \\
\text { Scales } \\
\text { (component } \\
\text { items are } \\
\text { shown in } \\
\text { brackets) }\end{array}$} & \multicolumn{6}{|c|}{ Mothers of under-five vears children } \\
\hline & & $\begin{array}{l}\text { Total } \\
\text { means } \\
\text { from } \\
\text { component } \\
\text { items }\end{array}$ & $\begin{array}{l}\text { Standard } \\
\text { deviation }\end{array}$ & $\begin{array}{l}\text { Means of } \\
\text { Satisfaction } \\
\text { Scales } \\
\text { (average of } \\
\text { means } \\
\text { deviation } \\
\text { from } \\
\text { component } \\
\text { items) }\end{array}$ & $\begin{array}{l}\text { Total } \\
\text { means } \\
\text { from } \\
\text { component } \\
\text { items }\end{array}$ & $\begin{array}{l}\text { Standard } \\
\text { deviation }\end{array}$ & $\begin{array}{l}\text { Means of } \\
\text { Satisfaction } \\
\text { Scales } \\
\text { (average of } \\
\text { means } \\
\text { deviation } \\
\text { from } \\
\text { component } \\
\text { items) }\end{array}$ \\
\hline 1 & $\begin{array}{l}\text { General } \\
\text { Satisfaction } \\
\text { (Items 3+17) }\end{array}$ & 6.03 & 0.84 & 3.02 & 5.89 & 0.89 & 2.95 \\
\hline 2 & $\begin{array}{l}\text { Technical } \\
\text { Quality (Items } \\
2+4+6+14 \text { ) }\end{array}$ & 13.83 & 1.69 & 3.46 & 13.45 & 2.01 & 3.36 \\
\hline 3 & $\begin{array}{l}\text { Interpersonal } \\
\text { Manner (Items } \\
\text { 10+11) }\end{array}$ & 7.41 & 1.70 & 3.71 & 7.49 & 1.79 & 3.75 \\
\hline 4 & $\begin{array}{l}\text { Communication } \\
\text { (Items } 1+13 \text { ) }\end{array}$ & 7.95 & 1.27 & 3.98 & 8.18 & 1.35 & 4.09 \\
\hline 5 & $\begin{array}{l}\text { Financial } \\
\text { Aspects (Items } \\
\mathbf{5 + 7 )}\end{array}$ & 7.51 & 1.61 & 3.76 & 7.81 & 1.58 & 3.91 \\
\hline 6 & $\begin{array}{l}\text { Time Spent } \\
\text { with Doctor } \\
\text { (Items } 12+15 \text { ) }\end{array}$ & 5.92 & 1.06 & 2.96 & 6.12 & 1.33 & 3.06 \\
\hline 7 & $\begin{array}{l}\text { Accessibility } \\
\text { and } \\
\text { Convenience } \\
\text { (Items } 8+9+ \\
16+18)\end{array}$ & 13.13 & 2.05 & 3.28 & 13.62 & 2.06 & 3.41 \\
\hline
\end{tabular}

Association of respondent's characteristics with satisfaction subscales for malaria care

To determine the relationship between each of the respondent's characteristics and satisfaction subscales for malaria care, a bivariate logistic regression was carried out. The results from the bivariate logistic regression are available in the supplementary file (S4). Among the pregnant women, only the interpersonal manner satisfaction subscale had significant associations with education and socioeconomic status. Statistically significant higher odds of satisfaction with the interpersonal manner of the health care professional offering malaria care was observed in the pregnant women with secondary (OR: $2.49,95 \% \mathrm{Cl}: 1.03-6.03)$ and tertiary (OR: $3.00,95 \% \mathrm{Cl}: 1.23$ - 7.33) level of education. Pregnant women in the upper social-economic class had significantly lower odds of satisfaction (OR: $0.31,95 \% \mathrm{Cl}: 0.11-0.89$ ) with the interpersonal manner of the health care professional offering 
malaria care. Among mothers of children aged under five years, those who were aged 35 years and above had a significant association with the general satisfaction subscale (OR: 2.57, 95\% Cl: $1.04-6.36$ ).

Table 4 presents the multivariate logistic regression for associations between education and socio-economic status of the pregnant women with the interpersonal manner satisfaction subscale. Among the pregnant women, only those with tertiary education showed a significant higher odd of satisfaction (OR: 3.19, 95\% Cl: $1.28-7.95)$ while those in the upper socio-economic class had a significantly lower odds of satisfaction (OR: 0.29, $95 \%$ Cl: 0.10 0.84) with the interpersonal manner of care offered (Table 4).

Table 4: Multivariate logistics regression results for association of explanatory variables with satisfaction scale for malaria care among.pregnant women

\begin{tabular}{|c|c|c|c|c|c|c|}
\hline \multirow[t]{2}{*}{ Satisfaction domain } & \multirow[t]{2}{*}{ Factor } & & \multirow[t]{2}{*}{ OR } & \multicolumn{2}{|l|}{$95 \% \mathrm{Cl}$} & \multirow[t]{2}{*}{ P-value } \\
\hline & & & & Lower & Upper & \\
\hline \multirow[t]{8}{*}{ Interpersonal Manner } & \multirow[t]{4}{*}{ Education } & No formal education & $\mathrm{R}$ & & & \\
\hline & & Primary & 1.99 & 0.36 & 10.97 & 0.429 \\
\hline & & Secondary & 2.44 & 0.99 & 6.03 & 0.053 \\
\hline & & Tertiary & 3.19 & 1.28 & 7.95 & $0.013^{\star}$ \\
\hline & \multirow[t]{4}{*}{ Socioeconomic status } & Lower class & $\mathrm{R}$ & & & \\
\hline & & Lower middle class & 0.72 & 0.25 & 2.06 & 0.541 \\
\hline & & Lower Upper class & 0.79 & 0.34 & 1.87 & 0.593 \\
\hline & & Upper class & 0.29 & 0.10 & 0.84 & $0.023^{*}$ \\
\hline
\end{tabular}

*Statistically significant $(p<0.05), R=$ Reference

On the other hand, the multivariate logistic regression carried out based on the significant associations identified in the bivariate logistic regression for mothers of children under the age of five is presented in Table 5. Statistically significant higher odds of satisfaction with the financial aspects of malaria care was observed among the mothers of children aged under five years who had primary and secondary level of education and also those in the lower upper socio-economic class. 
Table 5: Multivariate logistics regression results for association of explanatory variables with satisfaction scale for malaria care among mothers of children aged under five years

\begin{tabular}{|c|c|c|c|c|c|c|}
\hline \multirow[t]{2}{*}{ Satisfaction domain } & \multirow[t]{2}{*}{ Factor } & & \multirow[t]{2}{*}{ OR } & \multicolumn{2}{|c|}{$95 \% \mathrm{Cl}$} & \multirow[t]{2}{*}{ P-value } \\
\hline & & & & Lower & Upper & \\
\hline \multirow[t]{8}{*}{ Financial Aspects } & \multirow[t]{4}{*}{ Education } & No formal education & $\mathrm{R}$ & & & \\
\hline & & Primary & 20.47 & 1.26 & 332.86 & $0.034 *$ \\
\hline & & Secondary & 22.82 & 2.96 & 176.28 & $0.022^{*}$ \\
\hline & & Tertiary & 6.19 & 0.92 & 41.52 & 0.06 \\
\hline & \multirow[t]{4}{*}{ Socioeconomic status } & Lower class & $\mathrm{R}$ & & & \\
\hline & & Lower middle class & 2.05 & 0.56 & 9.37 & 0.251 \\
\hline & & Lower Upper class & 10.95 & 4.44 & 84.22 & $0.000 *$ \\
\hline & & Upper class & 3.65 & 0.92 & 35.07 & 0.061 \\
\hline
\end{tabular}

*Statistically significant $(p<0.05), R=$ Reference

\section{Discussion}

The current study is the first to use the PSQ-18 tool to evaluate patient satisfaction with malaria care in Nigeria and Sub-Sahara Africa. Satisfaction of patients with health care has been described as the degree to which a patient's desired expectations, goals and or preferences are met by the health care provider and or service [21]. Some studies $[22,23]$ have shown that patients are more likely to take appropriate preventive measures and adhere to their treatment plan if they were satisfied with level of care they were offered. The need for health systems to effectively deliver various dimensions of care, including patient-centred care is becoming ever more recognized that highquality medical care, in addition to improved coverage of maternal and child health services, is essential to achieving the Sustainability Goal's goal of reducing maternal and child mortality [24-26].

The findings from our study showed varying level of satisfaction for some of the items on the PSQ-18 tool and each of the seven satisfaction sub scales of the tool by the study respondents. We observed that for each item of the PSQ-18, our study respondents were poorly satisfied (mean score below 3 in Table 2) with items 14, 15, 17 and 18. Among the seven derived satisfaction sub-scales, there was a high level of satisfaction with the interpersonal manner and communication of care provided by health care providers as well as financial aspects of malaria care. Conversely, the pregnant women were least satisfied with time spent with doctors. Predictors of satisfaction with care, in particular interpersonal care provided to pregnant women, and the financial aspects of care as perceived by mothers of children under five years of age were their educational and socioeconomic status. Since no studies have 
used the same tool (PSQ-18) to evaluate satisfaction with malaria care by pregnant women and mothers with children under the age of five years, discussing and making a comparison of our study findings with other exactly similar studies is quite a challenge. Despite this challenge, we compared our findings with other studies that used the PSQ-18 to evaluate satisfaction with other non-malaria-related aspects of health care. We also compared our results with that of similar studies that used other data collection instruments to assess satisfaction with healthcare for malaria. We discovered that our study findings on pregnant women's satisfaction with duration of time spent with doctor was similar to results from a study conducted in Ghana which found that satisfaction with ANC was highly dependent on the duration of time spent in health facilities and quality of care received [27]. Another study conducted in Mozambique investigated the impact of a time scheduling system as an intervention to reduce duration of waiting time at the clinic and improve time spent with health provider. This latter study found that time scheduling as an intervention improved satisfaction with healthcare and increase utilization of ANC visits [28]. Improved and increased use of specifically high-quality ANC is crucial as it allows pregnant women to be informed about the potential danger signs during pregnancy and provides both treatment and prevention services for diseases such as malaria which could lead to adverse maternal and child health outcomes [28, 29].

The results from the multivariate analysis to determine the association between the study respondents' sociodemographic characteristics and each of the seven scales for patient satisfaction with malaria care showed some significant relationships. Education and socioeconomic status influenced the satisfaction of pregnant women with the interpersonal manner of care provided, while among mothers of children younger than five years, it influenced satisfaction with financial aspects of care. This study's finding is similar to that of one of the few studies that used the PSQ-18 to evaluate satisfaction with non-malarial aspects of care in South-East Nigeria, where educational level significantly facilitated satisfaction with healthcare received [30]. Other studies conducted in Ethiopia [31] and Italy [32] which assessed maternal satisfaction with non-malarial aspects of care using a different data collection tool also highlighted education as significant predictors of satisfaction with care. Moving on, this study finding on satisfaction with communication and interpersonal manner of care by the health providers supports the evidence that good communication between physicians and patients has a positive impact on patient satisfaction, thereby leading to improved compliance to treatment, decreased anxiety, increased recall and understanding of healthcare [33]. Also, the findings of this study on the impact of socio-economic status on malaria satisfaction are consistent with the report from a nationwide study in Zambia, which showed some socio-economic status indices such as education, income and place of residence [34], as predictors of satisfaction with malaria care which contributed to the mothers' health-seeking behaviour [35].

\section{Limitations}

Although the PSQ-18 that was used to collect data for this study is a valid, reproducible questionnaire [16], potential limitation to this study was response bias. The responses of individuals recruited at a hospital could have been influenced by the health condition that brought them to seek health care. Study participants were recruited based on their self-reported malaria symptoms that influenced them to seek health care. Another limitation is that it was not a multi-centre study that could have yielded a higher number of respondents and increased the generalizability of the findings.

\section{Conclusion}

Page $13 / 18$ 
This study found an above average level of satisfaction for most of each of the seven sub-scales measuring satisfaction with malaria care interventions. Level of satisfaction with malaria was particularly high for the sub scale on health care provider's interpersonal manner, communication and financial aspects of care. Low satisfaction was observed for the subscale on 'time spent with doctors' by pregnant women and 'general satisfaction' by mothers of children aged under five years. Patient satisfaction can sometimes be very subjective; however, because of the large sample size and methodical approach of the current study, we recommend that health care providers and stake holders take note of the findings herein. Low satisfaction is indicative of unmet health service delivery in the prevention and treatment of malaria. Clinicians and health service providers need to be more attentive and responsive to the expectations of patients seeking for malaria care. The policy implications of findings from this study emphasizes the need for conscientious effort to improve on health care delivery. Taking into consideration the vulnerabilities of pregnant women and children to malaria devastating impacts, government and non-governmental health stakeholders should organize women empowerment programs aimed at enhancing the literacy and socioeconomic status of especially pregnant women and mothers of children under the age of five years in the communities based on the role these women play as mothers of the home.

\section{Abbreviations}

ANC- Antenatal care

$\mathrm{Cl}$ - Confidence Interval

DHS - Demographic health survey

IPT- Intermittent preventive treatment for pregnant women

IRS - indoor residual spraying

ITNs - Insecticide-treated mosquito nets

LGAs - local government areas

MU5 - Mothers of children less than five years

NMIS - Nigeria Malaria Indicator Survey

OR - Odds ratio

PSQ-18 - Patient Satisfaction

PW - Pregnant women

SD - standard deviation

SPSS - Statistical Package of Social Sciences

\section{Declarations}

\section{Ethical approval and consent to participate}


The study was approved by the Biomedical Research Ethics Committee, KwaZulu-Natal University, South Africa (BREC-BE199/16) and the Oyo State Ministry of Health Ethics Committee, Nigeria (IRB AD13/479/1035). Only human participants were involved in the study. The participants enrolled in the study voluntarily gave informed consent to participate after gaining an understanding of the purpose and procedure of the study.

\section{Consent to publish}

Not applicable

\section{Availability of data and materials}

The dataset produced by the current study is available from the corresponding author upon request

\section{Competing interest}

The authors, including Prof. Sanni Yaya, an Associate Editor of the BMC Public Health Journal, declare no competing interests.

\section{Funding}

This project was supported by the University of KwaZulu-Natal College of Health Sciences postgraduate research scholarship award. The funder did not play any role in the design of the study, data collection, analysis, findings interpretation and writing of the manuscript.

\section{Authors' contributions}

KEO conceptualized the study, reviewed the literature, wrote the first draft of the manuscript with the data analysis plan. KEO, JJN, SNC, AMA analysed the data, KEO, JMTG, FLMH, SY, DTG critically reviewed the manuscript for its intellectual content. All authors read and approved the final manuscript. KEO had final responsibility to submit the manuscript.

\section{Acknowledgments}

The authors wish to acknowledge the Faculty of Health Sciences, University of Fort Hare for their continuous research support.

\section{References}


1. World Health Organization: World malaria report. Geneva: World Health Organization; 2019. Licence: CC BY-NCSA 3.0 IGO. In.; 2019.

2. National Malaria Elimination Programme - NMEP/Nigeria, National Population Commission - NPopC/Nigeria, National Bureau of Statistics - NBS/Nigeria, ICF: Nigeria Malaria Indicator Survey 2015. In. Abuja, Nigeria: NMEP/Nigeria, NPopC/Nigeria, NBS/Nigeria, and ICF; 2016.

3. Federal Ministry of Health (FMoH) Nigeria: National Guidelines for Diagnosis and Treatment of Malaria. In. Edited by FMoH, Third edn. Nigeria: FMoH; 2015.

4. World Health Organization: Universal access to core malaria interventions in high-burden countries. In. Geneva: WHO; 2018.

5. Thayaparan AJ, Mahdi E: The Patient Satisfaction Questionnaire Short Form (PSQ-18) as an adaptable, reliable, and validated tool for use in various settings. Medical Education Online 2013, 18(1):21747.

6. Alhashem AM, Alquraini $\mathrm{H}$, Chowdhury RI: Factors influencing patient satisfaction in primary healthcare clinics in Kuwait. International journal of health care quality assurance 2011, 24(3):249-262.

7. Al-Abri R, Al-Balushi A: Patient Satisfaction Survey as a Tool Towards Quality Improvement. Oman Medical Journal 2014, 29(1):3-7.

8. Gupta A, Dwivedi T, Sadhana, Chaudhary R: Analysis of Patient's Satisfaction with Phlebotomy Services in NABH Accredited Neuropsychiatric Hospital: An Effective Tool for Improvement. J Clin Diagn Res 2017, 11(9):EC05-EC08.

9. National Malaria Elimination Programme (NMEP): Nigeria Malaria Indicator Survey 2015. In. Abuja, Nigeria, and Rockville, Maryland, USA: National Population Commission (NPopC), National Bureau of Statistics (NBS), and ICF International; 2016.

10. Bouzid M, Cumming O, Hunter PR: What is the impact of water sanitation and hygiene in healthcare facilities on care seeking behaviour and patient satisfaction? A systematic review of the evidence from low-income and middle-income countries. BMJ Global Health 2018, 3(3):e000648.

11. Breiner H, Ford M, Gadsden VL, National Academies of Sciences E, Medicine: Parenting knowledge, attitudes, and practices. In: Parenting matters: Supporting parents of children ages 0-8. edn.: National Academies Press (US); 2016.

12. Adisa R, Agbom NN, Fakeye TO: Medication Use in Pregnancy: A Cross-Sectional Assessment of Pregnant Women at Antenatal Clinic of Adeoyo Maternity Teaching Hospital, Ibadan, Southwestern Nigeria. Nigerian Journal of Pharmaceutical Research 2016, 11(1):101-109.

13. Census Enumeration [http://population.gov.ng/core-activities/census-enumeration/]

14. Distribution of Local Governments by Geographical Zone [https://oyostate.gov.ng/ministry-of-localgovernment-and-chieftaincy-matters/distribution-of-local-governments-by-geographical-zone/]

15. Marshall GN, Hays RD: The patient satisfaction questionnaire short-form (PSQ-18). In.: Rand Santa Monica, CA; 1994.

16. Thayaparan AJ, Mahdi E: The Patient Satisfaction Questionnaire Short Form (PSQ-18) as an adaptable, reliable, and validated tool for use in various settings. Med Educ Online 2013, 18:21747-21747.

17. Ware JE: Development and validation of scales to measure patient satisfaction with health care services: Southern Illinois University [School of Medicine]; 1976. 
18. The Demographic Health Surveys (DHS) Program: DHS Model Questionnaires. Accessed 11 November 2015. Available from https://dhsprogram.com/What-We-Do/Survey-Types/DHS-Questionnaires.cfm.

19. Patient Satisfaction Questionnaire from RAND Health. Accessed 11th February 2018, Available from https://www.rand.org/health/surveys_tools/psq.html.

20. Ifediora CO, Rogers GD: Levels and predictors of patient satisfaction with doctor home-visit services in Australia. Family practice 2016, 34(1):63-70.

21. Nnebue CC, Ebenebe UE, Adinma ED, lyoke CA, Obionu CN, Ilika AL: Clients' knowledge, perception and satisfaction with quality of maternal health care services at the primary health care level in Nnewi, Nigeria. Nigerian journal of clinical practice 2014, 17(5):594-601.

22. Nunu WN, Munyewende PO: Patient satisfaction with nurse-delivery primary health care services in Free State and Gauteng provinces, South Africa: A comparative study. African journal of primary health care \& family medicine 2017, 9(1):1-8.

23. Kavalnienė R, Deksnyte A, Kasiulevičius V, Šapoka V, Aranauskas R, Aranauskas L: Patient satisfaction with primary healthcare services: are there any links with patients' symptoms of anxiety and depression? BMC Family Practice 2018, 19(1):90.

24. Larson E, Vail D, Mbaruku GM, Kimweri A, Freedman LP, Kruk ME: Moving toward patient-centered care in Africa: a discrete choice experiment of preferences for delivery care among 3,003 Tanzanian women. PloS one 2015, 10(8):e0135621.

25. Kruk ME, Larson E, Twum-Danso NA: Time for a quality revolution in global health. The Lancet Global health 2016, 4(9):e594-e596.

26. Kruk ME, Gage AD, Arsenault C, Jordan K, Leslie HH, Roder-DeWan S, Adeyi O, Barker P, Daelmans B, Doubova SV: High-quality health systems in the Sustainable Development Goals era: time for a revolution. The Lancet Global Health 2018, 6(11):e1196-e1252.

27. Asafo AJ, Adoma DB: Determinants of women's perceived satisfaction on Antenatal care in urban Ghana: A cross-sectional study. 2019.

28. Steenland M, Dula J, de Albuquerque A, Fernandes Q, Cuco RM, Chicumbe S, Gudo ES, Sequeira S, McConnell M: Effects of appointment scheduling on waiting time and utilisation of antenatal care in Mozambique. BMJ Global Health 2019, 4(6):e001788.

29. Bhutta ZA, Das JK, Bahl R, Lawn JE, Salam RA, Paul VK, Sankar MJ, Blencowe H, Rizvi A, Chou VB: Can available interventions end preventable deaths in mothers, newborn babies, and stillbirths, and at what cost? The Lancet 2014, 384(9940):347-370.

30. Chinemerem E, Agu IS: Patients' Satisfaction With Nurse Led Care In Selected Government Owned PrimaryHealth-Centres In South-East Nigeria. IOSR Journal of Nursing and Health Science (IOSR-JNHS) 2018, 7(4):2228.

31. Kebede DB, Belachew YB, Selbana DW, Gizaw AB: Maternal Satisfaction with Antenatal Care and Associated Factors among Pregnant Women in Hossana Town. International Journal of Reproductive Medicine 2020, 2020.

32. Tocchioni V, Seghieri C, De Santis G, Nuti S: Socio-demographic determinants of women's satisfaction with prenatal and delivery care services in Italy. International Journal for Quality in Health Care 2018, 30(8):594-601.

33. Mehnert A, Lehmann C, Koch U: Doctor-patient interaction: dealing with difficult situations. Bundesgesundheitsblatt, Gesundheitsforschung, Gesundheitsschutz 2012, 55(9):1134.

Page $17 / 18$ 
34. Lim C, Thanoon O: 2 - Social and Ethnic Determinants of Obesity. In: Obesity. edn. Edited by Mahmood T, Arulkumaran S. Oxford: Elsevier; 2013: 13-21.

35. Cassy A, Saifodine A, Candrinho B, Martins MdR, da Cunha S, Pereira FM, Samo Gudo E: Care-seeking behaviour and treatment practices for malaria in children under 5 years in Mozambique: a secondary analysis of 2011 DHS and 2015 IMASIDA datasets. Malaria Journal 2019, 18(1):115.

\section{Supplementary Files}

This is a list of supplementary files associated with this preprint. Click to download.

- KEOetaIPSMunscriptSTROBEchecklistcrosssectional.pdf

- mPSQ18.docx

- BivariatesLogisticsRegressionTablesSept2020.docx

- psq18scoringguide.pdf

- DataforPSmanusript.xls 